\title{
Technik: the relevance of a missing concept
}

M. Fores, of the UK Department of Industry, and l. Rey, previously of the Swedish Ministry of Industry, offer their personal suggestion that the absence of an English word to describe the 'useful arts' of manufacture leads to unnecessary confusion in talking about the world of manufacturing

WrITERS in the English language often use words in such a way that 'science' and 'technology' are considered as key features affecting manufacturing. Sometimes they are even wrapped together and simply known as 'science'. Hilary and Steven Rose, for instance, do this in their book Science and Society. Such a usage incorporates a number of errors concerning what was once known as the 'useful arts' of manufacture. To show this, we introduce the word Technik which is widely used and understood in Germany. It concerns the functioning of natural and man-made things, including the set of principles according to which artifacts work and the methods used in making them. Most continental European languages include such an idea.

One English language study which erred over the general influence of 'science' in the culture was Bronowski and Mazlish's The Western Intellectual Tradition (Penguin). They wrote:

What is needed is that in the general history books the development of science should take its place along with political and economic developments. The steam engine helped to shape the modern world at least as much as Napoleon and Adam Smith, but only rarely do historians admit the fact . . .

Few would dispute that the steam engine has had an important influence on the modern world; but it cannot sensibly be thought of as a 'product of science'.

In Germany, if there are two cultures or sub-areas of the general culture, they are not the science and humanities of the English split. They are Wissenschaft, concerned with all knowledge and all the subjects of the classical university, and Technik. Normally, however, there are three subcultures: Kunst 'art', the English 'fine arts' and performing arts; Wissenschaft; and Technik, widely accepted to be separate from both. Wissenschaft means the art of handling knowledge, akin to 'gamesmanship' and seamanship'.

The importance of Technik stems from the fact that it has been a prime concern of the species from earliest times. Some of its first products were stones sharpened to kill animals for food, or to ward off dangerous animals. Man became a tool-maker and tool-user through Technik.

The history of Technik is not, however, the conquest of nature. Problems of Technik are not seen in terms of nature but rather of a specific job to be done or an artifact to be made. And more complex contrivances strayed further from the natural state of their component materials. A stick, as a lever, was made of wood, directly from the natural world. But a potter's wheel could be made from various materials, probably in combination. And a governor to control the speed of a rotating machine is a contrivance to control a contrivance. Thus the exponent of Technik must be obsessed with the artificial, rather than the natural. If the operations of Technik shade into those of either of the other two cultural areas, they shade into Kunst, rather than Wissenschaft. Metal-working skills are an obvious example of craft skills that have been shared between making the products of fine art and useful artifacts.

The 'applied science' concept is a peg on which some have hung their views about manufacturing. Only in English, of the major European languages, can the concept exist, since only English has a meaning for the word science which only includes knowledge of natural pheno- mena, or the process by which this knowledge is derived. By use of the 'applied science' phrase, the process of Technik is made to seem closer to the natural world than it is in practice.

The applied science concept is misleading for other reasons. It implies that a contrast can exist with pure science. Yet there can never be any body of pure science at all, if the criterion used is lack of utility, or lack of applicability of knowledge. All scientific knowledge is put out freely for verification of falsification-so all can be used freely and with no attribution. The most basic ideas of natural science, such as Newton's laws of motion, turn out to be widely applicable in practice. So the bizarre conclusion must be drawn that the purest of science is more widely applicable in practice than work which is done for particular uses, so-called applied work. Applied science as a sensible near-alternative to Technik fails because manufacturing cannot be well characterised as the application of scientific knowledge. Furthermore, studies have shown that the rate of technical progress in manufacturing cannot be equated with the rate of adoption of science.

Continental-style technologie invariably means what one would expect from its Greek roots (techne means art; logos means word or law), so it is not the same as Englishlanguage technology. British official statistics show that most technologists are engineers; they are not like other types of '-ologists', students of events. The use of the concept of Technik avoids this misunderstanding.

Another difference between perceptions of Technik and of technology comes with the idea of utility. Acts of Technik are accepted to be pointless if there is no demand, within the existing cost pattern, for the useful artifact being made. There are no imperatives of Technik along the lines of technological imperatives of the English-language, whereby critics complain that because something can be made it will be made.

Another feature is that Technik does not rule well in an aristocratic or a dictatorial situation, if only because it depends more on detail than on principle. The best conception for a contrivance, or the best design for it, is of no use if the detailed manufacture of component parts is not up to standard. The whole may not be greater than the sum of the parts; but if one of the parts is defective, the whole cannot function.

Continental Technik is accepted to be a separate cultural area with codes of behaviour, responses and a dignity of its own. The competent Techniker does not feel that he has constantly to look over his shoulder at science or the arts, as the exponent of technology often does. Science and arts do not care much for utility and they have a different grasp of the artificial. Technik remains a missing concept in English; its absence is the English speaker's loss.

Sorry, for copyright reasons some images on this page may not be available online

Potter's wheel : an cxample of Technik 